\title{
LA VENUS ACUÁTICA DE CHELA REYES
}

\author{
Chela Reyes'Acuatic Venus
}

\author{
MARÍA INÉS ZALDÍVAR OVALLE \\ Pontificia Universidad Católica de Chile \\ mzaldiv@uc.cl
}

Resumen

Chela Reyes (1904-1988), es una escritora chilena nacida en Santiago el mismo año que Pablo Neruda. Ella tiene una relevante producción poética, casi desconocida, que puede y debería considerarse como parte de la tradición de la vanguardia histórica chilena. Este trabajo pretende evidenciar cómo en Ola nocturna, su tercer poemario publicado en 1945, la autora utiliza personajes y referencias de la mitología griega para dar forma a su imaginario. Su universo figurativo está constituido por poderosas evocaciones de un espacio marítimo en el que se confunde Eros y Tanatos. Personajes como Eolo, Hipocampos, Sirenas, Neptuno, Eco, Venus, forman parte de su galería mitológica-poética. Mediante estas figuras la poeta construye un mundo sorprendente y fascinante en donde el erotismo es tanto creación como destrucción.

Palabras clave: Chela Reyes; Poesía chilena; mujeres y vanguardia; mar; mitología clásica

Abstract:

Chela Reyes (1904-1988) is a chilean writer born in Santiago, the same year as Pablo Neruda. She has a relevant poetic production, almost unknown, that can and should be considered as part of the tradition of the Chilean historical avant-garde. This work aims to show how, in Ola nocturna, her third book of poems published in 1945, the author uses characters and references from Greek mythology to shape her imaginary. Its figurative universe is constituted by powerful evocations of a maritime space in which Eros and Thanatos are confused. Characters such as Eolo, Hippocampus, Sirens, Neptune, Echo, Venus, are part of its mythological-poetic gallery. Through these figures the poet builds a surprising and fascinating world in which eroticism is both creation and destruction.

Key words: Chela Reyes; Chilean Poetry; Women and Vanguard; Sea; Classical Mythology

\section{LA AUTORA}

María Zulema Reyes Valledor es el nombre de pila de Chela Reyes (Santiago 1904-1988) nacida el mismo año que Pablo Neruda. Su quehacer escritural es muy precoz; a los ocho años de edad se inicia con pequeñas publicaciones, y ya a finales de la década de los veinte, realizaba colaboraciones en distintos diarios nacionales como El Diario Ilustrado y La Nación.

Su obra es variada: publicó poesía, cuento y novela, teatro y literatura infantil. Sabemos también que trabajó en diversos programas radiales, que fue durante cuarenta y 
dos años miembro y secretaria del Pen Club de Chile, que junto con Pablo de Rokha fundó el Sindicato de Escritores, y una de las primeras mujeres en Chile que recibió el título universitario de Visitadora Social adquirido durante su estadía de tres años en Venezuela. Su obra poética consta de los títulos: Inquietud, publicado a los veintidós años de edad en 1927; Época del alma (1937); Ola nocturna (1945); y Elegías (1962). Alone afirma que "Chela Reyes usa el mundo como la plataforma el bailarín para apoyar los pies y lanzar el resto hacia la fantasía [...] El tono dominante lo constituye la atmósfera, como de sueño, el placer de respirar, de ver y de oír en el aire el libre desencadenamiento de las imaginaciones" (El Mercurio, 1945, pp. 27-1-74). Por otra parte, Naín Nómez plantea que su poesía es "abierta a la aventura... [y en ella] La pasión es plena, el goce es sensual y el poema un campo de batalla en que la tensión se resuelve en potencia y movimiento de un sujeto activo cruzado por el torbellino de las metáforas de lo vital" (Nómez, 2000, tomo II, p. 291).

Así fue como recibió algunos premios relevantes: en Chile el Premio Atenea de la Universidad de Concepción en 1939 por su novela Puertas verdes y caminos blancos y, en 1970, el Premio Hans Christian Andersen, que es el más alto reconocimiento internacional otorgado a un autor y a un ilustrador de libros para niños y jóvenes, otorgado por la Organización Internacional para el Libro Juvenil (IBBY) fundada en Zurich (Suiza) en $1953^{1}$.

El poemario Ola nocturna, fue publicado en 1945 en Santiago de Chile, en la Impresora de La Casa Nacional del Niño, bajo el sello Ediciones La Semana Literaria, y en un tiraje de 500 ejemplares, que sigue siendo la única edición existente (o más bien dicho inexistente). Un dato interesante a considerar para su lectura, es la apreciación que la propia autora tiene acerca del poemario. En una carta fechada el 5 de diciembre de 1945 dirigida a Gabriela Mistral para felicitarla por el Premio Nobel, desliza en el penúltimo párrafo lo siguiente:

Quisiera saber en qué lugar del mundo la irán a alcanzar estas letras! desde luego se las enviaré a Estocolmo, pues estoy informada que estará allá el ocho de este mes. Dios quiera que las reciba. Ahora viene la pregunta... Recibió mi último libro Ola nocturna que le envié hace un mes a Petrópolis, por medio del Ministerio de Relaciones? Quiero saber si está en su poder, pues tengo vivo interés por que lo lea. Es un libro que yo quiero mucho (Reyes, 1974)².

\footnotetext{
${ }^{1}$ Esta organización es un colectivo sin ánimo de lucro. Está compuesto por asociaciones y personas de todo el mundo comprometidas con la idea de propiciar el encuentro entre los libros y la infancia. El premio le fue otorgado por su cuento infantil La pequeña historia de un pececito rojo.

${ }^{2}$ Carta de Chela Reyes a Gabriela Mistral: http://www.memoriachilena.cl/602/w3-article-132054.html Menciono también otro antecedente de la relación literaria entre ambas poetas; hay un conjunto de breves comentarios de escritores y críticos reconocidos acerca de la obra de Chela Reyes, al final de su libro de cuentos Las cadencias secretas (1974). Uno de esos es de Gabriela Mistral y referido a la novela Puertas verdes y caminos blancos de 1939; transcribo:
}

114 | AlPHa No50 (Julio 2020) PÁGS. 113-124. ISSN 07 16-4254 
La predilección por este texto que menciona en la carta, también se observa en una declaración de 1951 que realiza para el diario Las Últimas Noticias, dice: "Creo que mi mejor libro de versos es Ola nocturna. Estoy convencida de que no podría escribir nada mejor (Citado por Luis Merino Reyes, 1988)" (Nómez, 2000, p. 290).

Las lecturas críticas de este poemario relativamente cercanas a su fecha de publicación son casi inexistentes, salvo una leve mención que me parece destacable y que nos conecta con el tema que nos convoca. Me refiero a una de Ricardo Latcham:

Los motivos marítimos, de fácil y episódico tratamiento en muchos poetas, son para Chela Reyes un campo vastísimo de personales atisbos y de inmersiones en ciertas zonas complejas del sentimiento, las mismas que dan la nota del lirismo trascendental y de las grandes metáforas a que nos tiene acostumbrados Pablo Neruda en sus cantos oscuros y potenciales (Reyes, 1974, p. 119) ${ }^{3}$.

El señalamiento de lo marítimo como matriz de sentido en la poética de la autora se repite más de veinte años después, en la Antología de poetas chilenas Confiscación $y$ silencio de Eugenia Brito al mencionarse que estamos frente a "una poeta que hace del agua, lo femenino y de la muerte, lo humano, una convergencia metafórica que la ubica, por lo menos en sus textos más logrados (Ola nocturna y Elegías), como una de las más brillantes precursoras de la poesía contemporánea" (Reyes, 1998, p.95).

Investigaciones recientes, incluso aún inéditas, reflexionan con lucidez acerca del texto en cuestión. Rodrigo González Dinamarca, al igual que Latcham y Alone, acoge la vinculación entre la poética de Pablo Neruda y Chela Reyes, y para ello el investigador apunta que:

En su escritura, como veremos, Reyes se apropia de metáforas y lexemas particularmente nerudianos, y los resignifica desde este otro polo de enunciación: su

De Gabriela Mistral: (De uno de sus "recados" en El Mercurio)

He tenido en el año que pasó y en el entrante, cuatro fuertes y lindas alegrías: leer en Cuba un libro de Dulce María Loynaz, leer otro de Isa Caraballo y de María Luisa Bombal, hermoso libro, y leer el suyo Chela, su hermosa novela hecha y derecha..." Es un signo indudable e impresionante de la creación despierta y valiente de la mujer americana que ya no tiene miedo y que tampoco tiene ignorancia de técnicas, porque ya posee el idioma en abundancia..." Lo que yo tengo que expresarle es mi vivo agradecimiento por haberme hecho repechar con dulzura y gozo muchas cosas de la adolescencia..." No sé ahora qué deseo más: que Ud. siga en este género en el cual ha acertado de golpe o que haga poesía. Tal vez halle Ud. Modo de seguir esa ruta doble en muchos, paralela. Aunque yo creo que "se pelean" en el alma el verso y la prosa de una pelea violenta" (Reyes, 1974, p.120).

${ }^{3}$ Me refiero nuevamente al conjunto de breves comentarios de escritores y críticos acerca de la obra de Chela Reyes, al final de su libro de cuentos Las cadencias secretas (1974).

Esta vinculación poética entre Pablo Neruda y Ola nocturna de Chela Reyes, había sido mencionada por Alone el mismo año de publicación del poemario al señalar que la poeta: "gira, aunque con mucha amplitud y enérgica soltura, dentro de la órbita nerudiana” (El Mercurio, 28-10-1945). 
voz viene de más allá del mar, o del fondo del mismo. Tales imágenes, como la de la mujer-mar devorador o la mujer-barco, aparecerán usadas en la construcción de un erotismo amenazante, vampírico y abisal que, propongo, constituye una respuesta al discurso amoroso instaurado por los Veinte poemas de Neruda".

Si ponemos en contexto la temática a tratar, dentro del corpus poético de las cuatro poetas que conforman la investigación en curso, y dentro de lo que se inserta la reflexión de hoy, se puede apreciar que, en todas ellas y, de alguna manera, existe una poetización de lo marítimo. El mar y sus circunstancias, si se pudiera decir, es un espacio recurrente en la pluma de estas escritoras chilenas. Presento a continuación una breve mención a cada una para ilustrar lo señalado. Olga Acevedo, en su poema Desamparo de Los cantos de la montaña (1927) escribe: “...He perdido luz... ¿Cómo veré?/ Una inmensa ola negra me ha precipitado en este abismo... ¿Quién me guiará?” (Canto I, p. 58); o más adelante, en Las cábalas del sueño (1951), donde la entrada al mar es sumergirse en un sueño feroz, se lee: "Entro en el agua profunda y abro los pétalos silenciosos como ventanas a la luz" (Canto VI, p.449). Y, más adelante: "Las olas desposeídas se adelgazan y solo queda un vasto manto de alas quietas y copas decapitadas. / No olvidemos que en su piedra profunda, el corazón dormido, tiembla... (p. 449) [...] Debo alzar mi memoria fugitiva y avanzar hasta los últimos arrecifes?" (p. 50). Para continuar en el Canto siguiente intensificando la ferocidad mencionada con expresiones tales como:

Por debajo de ese manto mojado, discurren ciertamente los terribles tentáculos devorantes y los feroces íncubos ocultos.

Es el mar muerto de los muertos. Cómo escapar a su trampa siniestra, sus largos brazos imantados, su ciega noche inadvertida? [...]

Cuesta sacudir los pulpos y las larvas mortíferas, sudores de sangre cuesta la asfixia cuerpo a cuerpo con las furias malditas (Acevedo, 1951, Canto VI, 451)

Winétt de Rokha también poetiza el mar y lo hace en su propio tono, como puede apreciarse en poemas de Oniromancia, publicado en 1943. En el extenso poema Cadena de verbos nos habla una voz de mujer campesina que habita en tierra firme, pero que mira desde una "Ventana desteñida, acuaria" (De Rokha, 1943, p. 257), allí: "Todo gira, en ese vaivén de barco o nube o pensamiento, / porque crío en el alma esa transparencia / que tienen las ideas del mar, los ríos y las lágrimas" (p. 257). La hablante se atreve a mirar, a recordar (es decir, a volver a pasar por el corazón), y aunque "aterrada y confusa", abre su "corazón hacia el mar hirviente" (p. 259). O, nuevamente re-cordando, contempla ese mar de la infancia que leemos en la segunda estrofa del poema Gotera de dulce diamante: "El mar que cubrió, sublimemente, / mi niñez pequeñita y atormentada, / mirándome con su enorme ojo acuático de animal sacrificado, / inmensa y trágica esmeralda" (p. 278). Y cito el poema El sueño de las algas, que termina diciendo: "El sueño de las algas, guarda un 
secreto / escrito en siete perlas color de cuento azul, / cuando las mujeres entran desnudas a la seda del océano" (p. 283).

Por último María Monvel a quien, aun provisoriamente, puedo visualizar como una poeta en la que el mar es un espacio para el encuentro amoroso, la metáfora de un refugio, como se lee en “¿Dónde se fue mi vida?”, texto de Últimos poemas (póstumo, 1937): "Quiero la noche obscura / en donde tu alma duerma / Quiero tus mares hondos / o bien tu obscura piedra. / Quiero un hueco en la almohada / donde está tu cabeza" o más decididamente el mar como la presencia del deseo de un amor marítimo: "Agridulces deben ser / los besos del marinero / salpicaduras del mar / en los labios entreabiertos" La vivencia del amor con esos hombres amantes de las sirenas y que "por eso tienen los ojos / teñidos de sus misterios" (Monvel, 1934, pp. 87-88)4. Mar, amor y viaje, en conjunción, como en el poema 5 de Invitación al viaje, con la voz de una navegante nocturna que desde cubierta contempla una: "Luna del trópico, ancha y derretida como la mantequilla en verano" (p. 137), esa luna que "simula el ojo dilatado y blanco de un moribundo", mientras "El mar, un mar que es una sombra, respira con blandura..." (p. 138)

Retomando a Chela Reyes quisiera hacer presente cómo la mitología clásica -con excepción solo de un poema, Tótem, que alude a otro tipo de mitología ${ }^{6}-$ es un tema que atraviesa toda esta Ola nocturna. Basta con mirar los títulos y las figuras que deambulan por sus páginas. Eolo, Neptuno, Eco, Hipocampos, Sirenas, Venus, pueblan su galería mitológica-poética, y se dibujan con variadas luces, sombras e intensidades. Es Eolo, ese del cual: "un torbellino crece en $\mathrm{t}[\mathrm{s}] \mathrm{u}$ cintura /y un halo de vapor en t[s]u garganta, / y una bandada de delfines ciegos / sigue t[s]u voz en redondelas albas!" (Reyes, 1945, p. 25). Es también la sirena, esa poderosa híbrida que tanto atrapa como consuela al navegante de "la mirada rota" y que "en la dulzura de una paz marina / alisas tu cabello alborotado / y afinas tu tremenda caracola" (p. 30). O esos hipocampos que "Arrodillados van derramando / dormida luz y encaje moribundo / en un galope de cansado aliento / hacia la orilla de frescor del mundo" (p. 37), pero que "illevan quemados los ijares verdes / por el talón caliente de Neptuno!' (p. 37). Y es también el delfín irreverente, quien juguetea con el mismo Neptuno, rey de los mares, "y por su seno va[s] cruzando /como gentil cometa rosa, / y su tridente t[1]e acaricia / la juvenil y rauda cola" (p. 59), o la bella y locuaz ninfa silenciada, eternamente enamorada de Narciso, Eco, que susurra: "Deshecha estoy de luna, sometida, / rendida de tu boca enamorada, / para siempre, en el tiempo de la sombra" (p.69).

\footnotetext{
${ }^{4}$ Este texto fue escrito por María Mombel en 1929 y pertenece al poemario Sus mejores poemas, publicado en 1934.

${ }^{5}$ Este párrafo ha sido copiado y pegado de una presentación de mi autoría, desde la pagina web https://edicionesliz.blogspot.com/2018/03/presentacion-coleccion-desenterradas.html

${ }^{6}$ Poema, que alude más bien a una mitología tribal.
} 
Mi lectura esta vez se centrará en Venus, poema que lleva el nombre de la diosa romana cuyo referente es Afrodita, aquella nacida de la espuma del mar tras la castración que el hijo, Cronos, hace de su padre, Urano, y tal como es relatado por Hesíodo: "A su alrededor, surgía del miembro inmortal una blanca espuma y en medio de ella nació una doncella" (Pérez y Martínez, 2000, p.19). Es aquella divinidad de la casta de Zeus a quien, según el relato de La Ilíada, este le dice: "Hija mía, a ti no te están dadas las bélicas empresas. Tú ocúpate de las deseables labores de la boda" (Canto V 370, p. 94).

\section{VENUS}

Como una flor pesaba su cadera, como una luz hería su dulzura y era su boca definida y pura como la risa de la primavera. ¡Y por sus muslos deslizaba el viento la roja lengua de su ardiente espera!

Desde la ola en nacimiento, era eternamente llena de hermosura. Morían peces de una muerte oscura entre la fronda de su cabellera. ¡Y así vestida de soleada lumbre vertía gotas de celeste cera!

Y era una rosa como una quimera en verde cáliz de abismal hondura donde mecía su cimera pura la amarga ola en su obstinada esfera, ¡mientras clarines y ángeles cantaban el nacimiento de una primavera!

Pero ella terca y sensitiva era, bajo su piel quemaba la amargura, y por sus ojos una lumbre pura iba naciendo hacia la vida entera. ¡Una mujer que florecía absorta desde unas aguas, en sedienta espera!

\section{DIOSES Y VERSOS}

El poema, en cuatro simétricos y armónicos sextetos, dibuja ecfrásticamente acerca de una de las páginas de Ola nocturna, ese nacimiento inmortalizado por Sandro Boticelli entre 1482 y 1485 . Pero ya en una primera lectura de sus versos esta diosa, emblema de la 
mujer bella, armoniosa, a cuyo destino al decir de Zeus no le "están dadas las bélicas empresas", si no más bien ocuparse "de las deseables labores de la boda", nos lleva por otros caminos que concuerdan con lo señalado por Naín Nómez pues, aunque en el poema se percibe el goce sensual de sus imágenes, también estamos en un campo de batalla, en un campo minado. Es palmario que la poetización de Chela Reyes esconde tras su ordenada y limpia factura métrica y estructural, una "Venus" que se resiste al simple goce contemplativo, sereno y armónico. En su defecto, estamos frente a un sujeto bello, aparentemente pasivo, pero que genera efectos contradictorios ya que, aunque "Desde la ola en nacimiento, era / eternamente llena de hermosura" (p. 77), a su alrededor "Morían peces de una muerte obscura / entre la fronda de su cabellera" (p. 77). Se nos presenta a una diosa que emerge del mar y que en ese mismo instante produce una estela de muerte a su alrededor. Se puede afirmar entonces que su nacimiento desde el agua conjuga tanto la vida y la belleza, como la muerte y la oscuridad.

Por otra parte, esta ambivalencia cargada con un sello antitético daño-beneficio, se caracteriza por producir ondas expansibles y efectos de traslación. Leamos la tercera estrofa: "Y era una rosa como una quimera / en verde cáliz de abisal hondura / donde mecía su cimera pura / la amarga ola en su obstinada esfera, /¡mientras clarines y ángeles cantaban / el nacimiento de una primavera"(p. 78). Como vemos, por una parte es expansible, ya que el poema se desplaza de lo marítimo hacia lo aéreo; ahora aparecen también los ángeles - que siguiendo la mirada ecfrástica serían en realidad Céfiro y Cloris- quienes cantan con sus clarines en el cielo y, por la otra, es intercambiable, pues, ya no son solo los peces quienes tienen "una muerte obscura / entre la fronda de su cabellera", sino que la propia Venus, aunque emerge desde las profundidades, reside y al parecer seguirá residiendo "en verde cáliz de abismal hondura" (p. 78). Puede apreciarse por tanto que, si en la segunda estrofa Venus nace y los peces a su alrededor mueren, en la tercera la diosa recién nacida es solo la quimera de una rosa pues no corta el cordón umbilical que la ata a ese terreno acuático oscuro, impreciso, quimérico, abismal. Debido a esto se diluye su arribo al mundo, a tierra firme, para enraizarse -en cuanto rosa que es, según el texto- pues, mientras cantan los seres celestiales y los peces mueren bajo el mar, ella queda amarrada a sostenerse sobre una amarga ola.

La ambivalencia por tanto se hace compleja, pues ya no estamos en el binario cielo mar, sino más bien en un triángulo que se mueve entre lo aéreo jubiloso, vital; lo marítimo amargo, letal; y lo terrenal sólido pero quimérico. Ahora bien, especulando en esta misma línea de análisis, puede pensarse que esta Venus de Chela Reyes que se equilibra en este triángulo -cielo, mar, tierra- (vida-espera-muerte), está cargada, marcada, por el tácito origen de la diosa, su origen violento y mortífero de castración y generación. En pocas palabras, especulo, el texto estaría dibujando sobre las olas un ser que nace con el estigma de haber sido engendrado desde la muerte, y que su karma será vivir en sedienta espera, como se lee en el último verso del poema. 
Incorporando el elemento tierra del triángulo mencionado y más específicamente lo floral, presente en el texto, Rodrigo González Dinamarca en esta misma línea de lectura, problematiza el goce sensual que produce este fruto de la naturaleza, diciendo que "este ámbito no se desenvuelve, como cabría esperar, de una manera dulce o simplemente placentera" [puesto que], "La flor no es aquí objeto plácido de la contemplación, no es liviana ni tranquilizadora: hay pesadez, hay herida asociada a la visión de su figura" (Capitulo X, p. 234), señalando que lo que se destaca de la flor "es una cierta materialidad angustiante, la de la pesadez y, nuevamente, la del abismo" (Capítulo X, p. 234). Como se puede apreciar, al igual que en la relación cielo-mar-si consideramos la flor como una sinécdoque de tierra-, este binario ahora mar-tierra, también se configura en términos de daño-beneficio, como aquello bello-bueno que daña y que, siguiendo esta onda expansiva de la que hablaba, se extiende a otros elementos fundamentales y arquetípicos de la naturaleza como lo son el viento y el fuego, pues: " $i[. .$.$] por sus muslos deslizaba el viento$ / la roja lengua de su ardiente espera!" (Reyes, 1945, p.77).

A estas alturas, no puedo dejar de vincular el poema, con lo señalado por Georges Didi-Huberman en su libro Venus rajada a propósito del cuadro de Boticelli. En su texto el autor va develando la tensión que esconde ese aparente plácido cuerpo desnudo de Venus estampado en la pintura, pues según sus propias palabras, "No cabe belleza celeste sin castración del Cielo" (p. 59). Puede reafirmarse entonces la idea de que por medio de la tensión que provocan estas imágenes binarias y triangulares que pesan, que hieren, puede entreverse en el poema la violenta castración original que subyace de su engendramiento, al igual que en la pintura, entre los versos del texto.

\section{EL MAR, SIEMPRE EL MAR}

Otra joven investigadora, Javiera Fuentes, también lee el poemario Ola nocturna y lo hace desde el mar, considerándolo como un elemento fundamental en la construcción de esta subjetividad femenina. Y, a propósito del poema homónimo que abre el libro, identifica la estrecha relación entre la "materialidad" del mar y la escritura del texto, señalando que se puede observar que la construcción del poema es como "una ola, que nace, crece y muere en el mar para volver a comenzar, así, eternamente" (Fuentes, 2017), ya que el inicio del primer verso de cada una de sus tres estrofas es: "nace bajo mi piel", luego "crece bajo mi piel" y por último, "muere bajo mi piel", respondiendo a los movimientos de la naturaleza en su proceso cíclico y estable. "La Ola nocturna del título se confirma y concreta en el texto mismo, por intermedio de su materia primordial: el lenguaje", afirma (p. 38).

En su defecto, si volvemos al mar de "Venus" -pues como vimos la "Venus" de Chela Reyes no es una deidad en tierra firme que se desplace por el Olimpo ni deambulando por múltiples parajes mundanos en correrías, pugnas y amoríos-, podemos apreciar que los 
movimientos de ese armónico mar inicial son otros; aquí es un "cáliz de abismal hondura" y una "amarga ola en su obstinada esfera", en medio de este hábitat se la retrata como figura central y en el momento preciso de su parto acuático. Es por ello que, en una lectura más demorada del poema, resulta ineludible focalizar la mirada en este elemento que la contiene, el agua, el mar y, aunque a nivel simbólico se ha escrito, analizado y codificado este elemento con insistencia, me parece oportuno reincidir.

Partamos recordando a Cirlot (2000) quien señala: "El mar, los océanos se consideran así como la fuente de la vida y el final de la misma. 'Volver al mar' es como 'retornar a la madre', 'morir"' (p. 305). Por otra parte, en el "El abrazo del mar" Martin Schatzmann plantea que el océano, ese mar inmenso que nos impresiona tanto por su fuerza como por el permanente vaivén de sus olas, tiene que ver con nuestra herencia genética porque, tal como sucede en este poema, "evoca emociones profundas que se asocian con el nacimiento de la vida a través del agua, como se refleja en la mitología" (Schatzmann, 2015, p.118).

Si nos detenemos ahora en El agua y los sueños de Gastón Bachelard asumimos que es posible fijar una ley de los cuatro elementos -fuego, aire, agua, tierra- vinculada a sus respectivas poéticas. Su reflexión identifica en la esencia misma del pensamiento de las aguas, del psiquismo hidratante, como lo denomina, una riqueza insospechada, estableciendo que el lector, por una parte, puede reconocer en la sustancia del agua un tipo de intimidad diferente de las sugeridas por las del fuego o de la piedra y, por la otra, que el agua es también un tipo de destino, "un destino esencial que sin cesar transforma la sustancia del ser" (Bachelard, 2003, p.15). Porque, según su planteamiento, comprender desde Heráclito el destino esencial del agua, que es permanentemente transitorio, permite asimilar, dolorosamente, que el ser humano también tiene ese mismo destino en su permanente fluir, y que "el ser consagrado al agua es un ser en el vértigo [ya que] sin cesar algo de su sustancia se derrumba" (p.15). Más bien se va derrumbando día a día, como el agua que siempre corre, que siempre cae, y que "concluye en su muerte horizontal" (Bachelard, 2015, p. 15).

Si se lee esta Venus de Reyes desde Bachelard asumiendo un psiquismo hidratante, que supone un tipo de intimidad acuática y se percibe un tipo de destino en constante fluir como el agua, claramente se puede identificar a la diosa como un ser suspendido en el vértigo, como un ser de vértigo. Considero que se presenta en el texto una bella serenidad solo aparente pues, como leemos en la primera estrofa, es cierto que "era su boca definida y pura / como la risa de la primavera" (Reyes, 1945, p. 77), pero no olvidemos que su cadera pesaba y estaba herida por la luz, y que el viento deslizaba por sus muslos "la roja lengua de su ardiente espera". Y si bajamos a la cuarta y última estrofa, la evidencia es más clara al comprobar que aunque era "terca y sensitiva", "Bajo su piel quemaba la amargura", pues la que nacía del agua era " $¡$ Una mujer que florecía absorta / desde unas aguas, en sedienta 
espera!' (p. 78). Paradojalmente, nace una mujer que florece, pero está absorta y, aunque surge rodeada de agua, permanece en sedienta espera. Tenemos por tanto que, detrás de esta fachada clásica de serenidad subyacen el peso, el dolor y, sobre todo, la espera, el vértigo permanente de lo no concluido, lo no satisfecho, que lleva a la ansiedad, que no es otra cosa que esa ardiente espera.

Para cerrar, una pregunta y un par de reflexiones. La pregunta. Félix Báez Jorge en Las voces del agua plantea que en el transcurso de la historia de la humanidad, una manera de legitimar la supuesta inferioridad de la mujer, o bien su condición de latente o manifiesta "peligrosidad numinosa", ha sido construir imágenes, como la de las sirenas. Textualmente dice que: "[...] en la imagen de las Sirenas se reúnen el encanto femenino con la terrible realidad de la muerte, eslabones fatales encadenados por el erotismo. La Sirena simboliza la encarnación femenina de la seducción enajenante. Proyección imaginaria que representa al otro, la entidad diferente que es, a un tiempo, fascinante y peligrosa" (Báez, 1992, p. 17).

A propósito de esta afirmación y relevando el hecho de que la chilena Chela Reyes incluye en su breve poemario Ola nocturna a las sirenas (lo sirenístico), ya sea dedicándole un texto ${ }^{7}$ como mencionándolo en varias oportunidades y, además, asumiendo a esta Venus de Reyes como un ser acuático, me surge una interrogante, ¿es ella uno de esos seres que responde al simbolismo de la mujer-agua como una respuesta al peligro que suponen las mujeres dentro del orden establecido? El análisis queda pendiente.

Las reflexiones. La primera; siguiendo a Bachelard en su psiquismo hidratante que reconoce en la sustancia del agua un tipo de intimidad y un tipo de destino, una idea central que me entrega la lectura de este poema es que, así como le sucede a la Venus de Chela Reyes, y asumiendo que lo viviente terráqueo viene del agua y su ciclo vital se cierra volviendo a su origen, y así sucesivamente (nacimiento - vida - muerte), la figura que está agazapada entre los versos del poema es la del ouróboros, la de la serpiente que se muerde la cola. La imagen del eterno retorno.

La segunda, es que si hacemos la traslación de la mitología grecolatina a la judeocristiana, el llamado pecado original de esta última podría ser el desasosiego, el nacer desasosegados por el vértigo que produce la inminencia de un futuro cierto e incierto a la vez pues, como le sucede a esta Venus, está siempre latente en la conciencia o inconsciencia del humano viviente, la naturaleza de este ciclo vital. En el poema de Chela Reyes se revela como una espera apremiante, tanto por la presencia del fuego: "ardiente espera", como por la falta del elemento vital para sobrevivir "sedienta espera". La marca de una espera, inquietud, desasosiego, que se podría también formular, derridianamente hablando, como un eterno desplazamiento original que nunca se satisface. Nacemos con el desasosiego de asimilar, de alguna manera, el vértigo que nos produce la conciencia de nuestra finitud.

\footnotetext{
${ }^{7}$ Poema Sirena (Reyes, 1945, p. 27).

122 | AlPHa No50 (Julio 2020) PÁGS. 113-124. ISSN 07 16-4254
} 
Este trabajo forma parte de una investigación mayor en curso que lleva por título: "Cuatro poetas de la vanguardia chilena: Winett de Rokha, Olga Acevedo, María Monvel y Chela Reyes" (Proyecto Fondecyt Regular No 1160096 (2016-marzo 2019). Fue presentado en el VI Congreso Mitos Prehispánicos y Mitos Clásicos en la Literatura Latinoamericana, en la Sapienza Universitá, Roma, 21 septiembre 2017.

\section{OBRAS CITADAS}

Acevedo, Olga (1951). Las cabalas del sueño. Santiago, Chile: Imprenta Nascimiento. (1927). Los cantos de la montaña, 1927. Santiago, Chile: Imprenta Nascimento.

Bachelard, Gastón (2003). El agua y los sueños: ensayo sobre la imaginación de la materia. Traducción Ida Vitale (1978). México: Fondo de Cultura Económica.

Báez Jorge, Félix (1992). Las voces del agua El Simbolismo de Las Sirenas y Las Mitologías Americanas. Veracruz: Ediciones Universidad Veracruzana.

Brito, Eugenia (1998). Antología de poetas chilenas Confiscación y silencio. Santiago de Chile: Dolmen Ediciones.

Crespo Güemes, Emilio (2000). Homero. Ilíada, Madrid: Gredos.

De Rokha, Winétt (2008). Winétt de Rokha El valle pierde su atmósfera Edición crítica de la obra poética. Prólogo, recopilación y notas de Javier Bello. Santiago de Chile: Cuarto propio

- (1943). Oniromancia. Santiago: Multitud.

Didi - Huberman, Georges (2005). Venus rajada. Desnudez, sueño, crueldad. Traducción Juana Salabert. Madrid: Editorial Losada.

Fuentes, Javiera (2017). Mar, noche y día: construcción de una subjetividad femenina en Ola nocturna de Chela Reyes, Seminario de título licenciatura en letras.

González Dinamarca, Rodrigo (2017-2018). Vagina dentada. Miedo, abyección en la poesía chilena. Tesis doctoral.

Monvel, María (1934). Sus mejores poemas. Santiago de Chile: Editorial Nascimento.

Nómez, Naín (2000). Antología crítica de la poesía chilena, tomo II. Poesía de las Vanguardias: Las transformaciones de la Modernidad (1916-1932). Santiago: LOM.

Pérez, Aurelio y Martínez, Alfonso (2000). Hesíodo: Teogonía, trabajos y días, escudo, Fragmentos. Madrid: Editorial Gredos. 
Reyes, Chela (1974). Las cadencias secretas. Santiago de Chile: Editorial del Pacífico, (1945). Ola nocturna. Santiago de Chile: Ediciones La semana literaria.

Schatzmann, Martin (2015). "El abrazo del mar. Acerca de la metáfora del mar y la simbología del agua en la poesía erótica española e hispanoamericana". Revista de Filología Románica no 8: 117-135. 